\title{
Comparison of snow water equivalent estimates calculated by SnoWE and ICON models on the example of the Kama river basin
}

\author{
Andrey Shikhov ${ }^{1 *}$, and Evgenii Churiulin ${ }^{2,3}$ \\ ${ }^{1}$ Perm State University, Bukireva 15, 614990, Perm, Russia \\ ${ }^{2}$ Lomonosov Moscow State University, Leninskiye Gory 1, 119991, Moscow, Russia \\ ${ }^{3}$ Hydrometcenter of Russia, 11-13 Bolshoy Predtechensky per., 123242, Moscow, Russia
}

\begin{abstract}
More recently, snow accumulation and snowmelt models for their calculations are forced to apply data from numerical weather prediction (NWP) models. This approach allows improvement the accuracy of calculating snow water equivalent (SWE) values especially in remote and mountain regions. In this study, we compared the numerical results of SWE calculations performed by two independent models. The first one is the SnoWE model and the second one is the ICON NWP model. During the period from November 2018 to May 2019, the simulation results of SWE compared with in-situ data from 64 snow surveys, which are located in the Kama river basin. We found that both models (SnoWE and ICON) allow getting satisfactory estimates of the maximum values of SWE (the accuracy of data is sufficient for their practical using). The root mean square error was equal $14-18 \%$ from the average measured SWE. Moreover, we got reliable maximum values of SWE for forested areas. At the same time, both models underestimate SWE values during spring snowmelt season. Probably, this underestimation is due to the shortcomings of the models and a sparse snow course-measuring network.
\end{abstract}

\section{Introduction}

Snow water equivalent (SWE) is one of the main characteristics of snow cover. The reliable data about the spatial distribution of SWE are required for modelling of spring floods, which are caused by snow melting. Moreover, modelling of spring floods has an effect on water management. Whereas, the last one is important for a number of sectors of the economy [1].

In-situ measurements (field and forest snow surveys) up until recently were the main source of SWE data. However, the snow surveys data has some limitations, such as relatively low frequency of measurements (once every 5 or 10 days), spatial irregularity,

\footnotetext{
* Corresponding author: and3131@,inbox.ru
} 
lack of the data in remote and mountain areas and the uncertainties which are related to their spatial interpolation.

Recently, many experiments on the assessment of SWE spatial distribution based on NWP models [2-5] and satellite data [6] have been performed worldwide. Since the spatial resolution of NWP models continuously improving, the opportunities of the reliable estimates of SWE also increase.

In Russia, the Hydro-Meteorological Centre (HMC) jointly with the international consortium COSMO developed the technology called 'SnoWE' to simulate snow accumulation and melting over the entire territory of the country $[1,7-8]$. In the SnoWE model is used a combination of short-term forecasts from the NWP model COSMO-Ru and in-situ observations on the weather stations. It had been implemented in quasi-operational mode since 2015 with a spatial resolution $2.2 \mathrm{~km}$ (for the Central Federal District), $7 \mathrm{~km}$ (for European part of Russia) and $13 \mathrm{~km}$ (for the entire territory of the country). The root mean square error (RMSE), estimated by comparing the simulated and measured SWE, ranged from 17 to $38 \mathrm{~mm}$ for various river basins of the European Russia [1].

Also, several regional studies on the same issue were carried out in Russia. In 2013 2016, a 4-years numerical experiment on snowpack modelling with the use of the Weather Research and Forecasting (WRF) NWP model has been performed for the Votkinsk reservoir basin, located on the north-east of the Kama river basin [9]. The uncertainty of WRF-based simulation of maximum SWE was estimated as 25-30\% of the measured values, but the model overestimated SWE at the second half of snow accumulation season.

In 2017/18, we simulated snow accumulation and snowmelt over the entire Kama river basin $\left(\mathrm{S}=507\right.$ thous. $\mathrm{km}^{2}$ ) with the use of publicly available daily forecasts of the global NWP models GFS (U.S.), GEM (Canada) and SL-AV (Russia). The simulation accuracy was approximately equal to WRF-based results [10]. During the cold season of 2018-2019, the same technique was implemented with the use of daily forecasts of ICON model, developed by the weather service of Germany. This model has the highest accuracy of winter precipitation forecast, comparing with other global NWP models [11].

Thus, two independent numerical experiments on snow accumulation and snowmelt modelling were carried out in the Kama river basin for the cold season 2018/19. As a result, we obtained the outputs of the SnoWE snowpack model $[1,8]$ and simulation based on the ICON model [12]. In this paper, we performed an inter comparison of such two datasets and estimated their accuracy based on field measurements data.

\section{Data and Methods}

\subsection{SnoWE model data}

SnoWE is one-dimensional multi-layer snowpack model driven by outputs of the NWP model COSMO-Ru and operational observations from the weather stations (surface air temperature, dew point, wind speed and precipitation). In the articles [1, 7] you can find more information about the snowpack simulation algorithms, data processing workflow, simulation results and their verification. The main feature of the SnoWE model in comparison with other snowpack models is the technology of daily correction of simulated snow cover characteristics, such as SWE, snow depth and snowpack density (RHO), based on daily measurements of snow depth at the weather stations. At the same time, the model has some drawbacks, for example, when calculating snow accumulation, the effects of snow interception by vegetation cover is not taken into account when calculating snow accumulation. 
In this study, we used daily outputs of the SnoWE model for 60 weather stations located within the Kama river basin, and also gridded values of SWE with 13-km cell size.

\subsection{SWE simulated with ICON model data}

The technique of GIS-based snowpack modelling with the use of daily NWP models forecasts combined with weather stations data is previously considered by us [9-10. 12]. In this study, we used daily values of simulated SWE (gridded data with 3-km cell size) and extracted them to the points of location of the weather stations. Since RHO and snow depth are not output variables when using this technique, we estimated only SWE values.

\subsection{Snow survey data}

Field measurements data have been obtained from 64 snow survey locations (routes) related to the weather stations of Russian hydro-meteorological service, including 41 routes in treeless areas and 23 routes in forests. Such data are considered as the points with SWE values (i.e. SWE averaged along snow survey route). They have been used to validate the simulation results in time steps of 5 or 10 days. Thus, we compared three different sources of SWE data (observed, the ones modeled according to the data from the SnoWE model and the ICON-based technique) for each point of the field measurements.

\section{Results and Discussion}

\subsection{Comparison of simulated SWE based on SnoWE and ICON models}

We compared the values of SWE, averaged over all weather stations located in the Kama river basin (Fig. 1 A). During the entire snow accumulation season of 2018/19, SWE values according to the SnoWE model exceeded the same values simulated by the ICON model on 10-20 mm. Such difference was formed mainly in the southern part of the basin. In midMarch, the SWE values according to the ICON model were on 9-11 mm (7-8\%) less than the ones modelled according to the SnoWE model. The RMSE of SWE data simulated with the help of the ICON model in comparison with the SnoWE model data fluctuated around $30 \mathrm{~mm}$ (approximately 19\% of average value of SWE).

During the spring snowmelt period, the difference between SWE simulated with the SnoWE and ICON models has substantially increased (up to 40-45 mm between April 5th and 10th). It is probably, that snow melting and sublimation according to ICON model were overestimated, which leads to the most rapid decrease of SWE.

\subsection{Comparison of simulation results with snow survey data}

Spatial distribution of the simulated SWE and in-situ measurements data in mid-March of 2019 (when average SWE over the Kama river basin reached a maximum value), are presented at Fig. 1 B. Fig. 2 and 3 shows the dynamics of measured and simulated SWE, (averaged by points located in treeless areas and in forests respectively) during the cold season 2018/19.

During the snow accumulation period (from November to mid-March), RMSE of simulated SWE increased slower than the SWE itself. Thus, the relative error of simulation results was minimal when SWE reached a seasonal maximum, which was observed in midMarch. At that time, RMSE of maximum SWE simulated with both SnoWE and ICON models was only $15-18 \%$ of average measured SWE. Thus, the simulation accuracy was 
substantially higher than the same previously estimated with the use of the WRF model [9]. However, during the spring snowmelt period, the ICON model and (less pronounced) the SnoWE model strongly underestimated SWE, and RMSE sharply increased. The SnoWE model provides most accurate results during this period, since its output data was corrected according to snow depth observed at the weather stations.
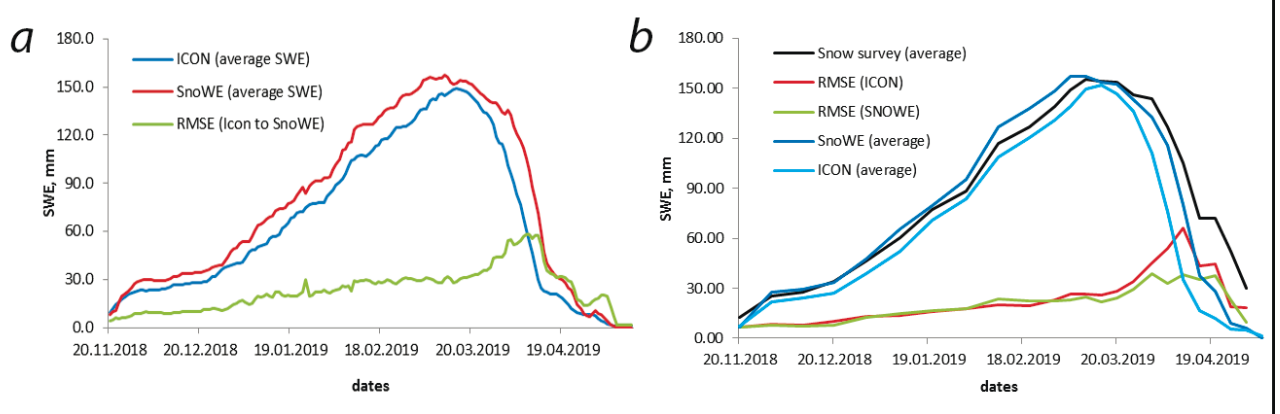

Fig. 1 Comparison of SWE averaged over the weather stations located in the Kama river basin according to the ICON and SnoWE models (a) and Comparison of the observed and simulated SWE on snow surveys located in treeless areas (averaged values for the entire Kama river basin) (b)

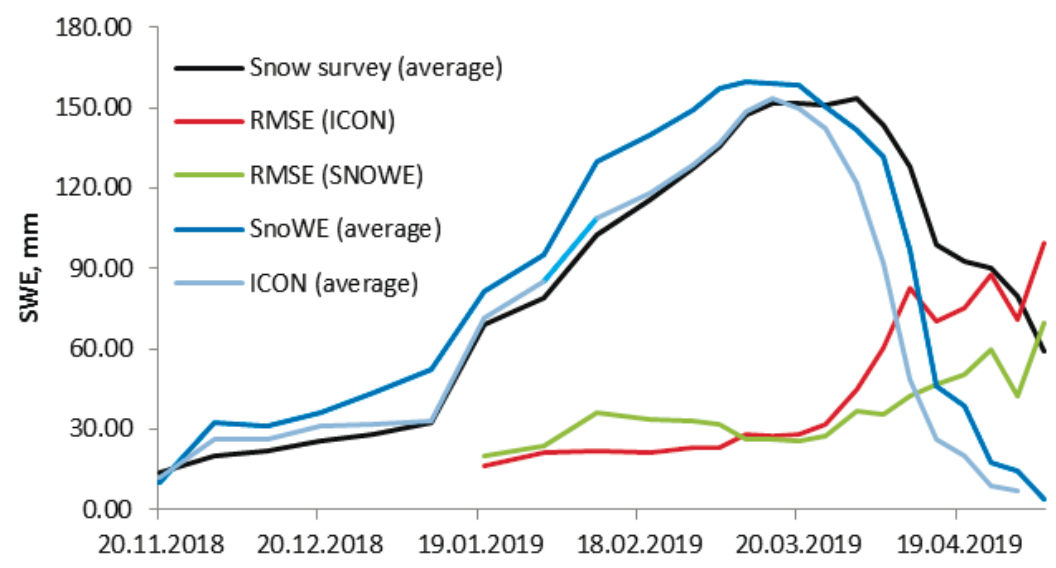

Fig. 2. Comparison of the observed and simulated SWE on snow surveys, located in forests (averaged values for the entire Kama river basin).

In treeless snow surveys, SWE simulated according to the SnoWE and the ICON models had no substantial biases in comparison with the observed values until mid-March. The maximum SWE according to the SnoWE model was reported between 5 and 10 March, that is few days earlier than the observed maximum. At the spring snowmelt season, both models substantially underestimated SWE. The underestimation sharply increased from the end of March and reached a maximum (25 mm according to the SnoWE model and $70 \mathrm{~mm}$ according to the ICON model) at the mid-April. Such strong biases may be related to the unrepresentative location of several snow survey routes and also to the overestimation of snowmelt and sublimation intensity (especially by ICON-based simulation). 


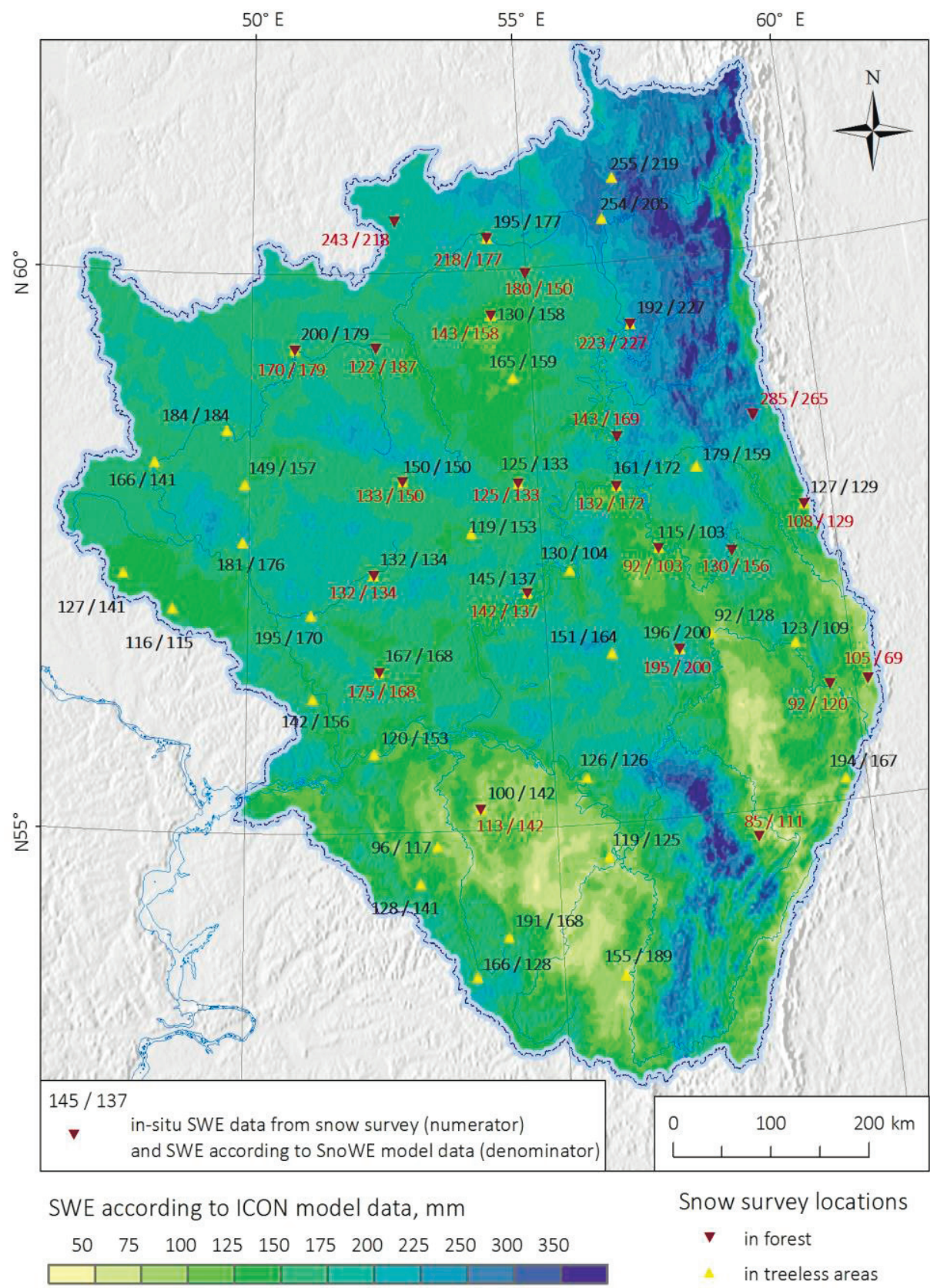

Fig. 3. Spatial distribution of the SWE according to ICON model (colour scale), and the SWE data according to the SnoWE model and in-situ observations at the weather stations (March 15, 2019).

At snow surveys in forests, SnoWE model slightly overestimated the maximum SWE (by $4-5 \%$ in average), and ICON-based simulation reproduced SWE most accurate during the entire snow accumulation season. However, the maximum SWE according to the field measurements was observed at the end of March, whereas the simulated maximum was 1520 days earlier. Then simulated SWE started to reduce, and at the snowmelt season it is 
strongly underestimated by both models. By mid-April, this underestimation reached approximately two times according to the SnoWE model and four times according to the ICON model. RMSE of simulated SWE also sharply increased.

Thus, we can conclude that both SnoWE and ICON models allows you to estimate the maximum SWE with the accuracy sufficient for practical use of the data (RMSE was 14$18 \%$ of the average measured SWE). In addition, the maximum SWE in forests was reproduced as reliable as in the treeless areas. In the same time, both models (especially ICON-based simulation) substantially underestimated the SWE during spring snowmelt season, which indicates both the shortcomings of the models and probably un representativeness of the field measurements in some locations.

The study was partially funded by RF President Grant Number MK-313.2020.5.

\section{References}

1. E. Churyulin, V. Kopeikin, I. Rozinkina, N. Frolova, A. Churyulina, Hydromet Stud. Forecasts. 368 (2018) (in Russian)

2. M. Verbunt, M. Zappa, J. Gurtz, P. Kaufmann, J. Hydrol, 324, 224-238 (2006).

3. S. Bellaire, J. Jamieson, C. Fierz, Cryosphere, 5, 1115-1125 (2011)

4. L. Quéno, V. Vionnet, I. Dombrowski-Etchevers, M. Lafaysse, M. Dumont, F. Karbou, The Cryosphere, 10(4), 1571-1589 (2016)

5. V. Vionnet, I. Dombrowski-Etchevers, M. Lafaysse, L. Quéno, Y. Seity, E. Bazile, J. Hydrometeor, 17(10), 2591-2614 (2016)

6. A. Telegin, N. Frolova, I. Kitaev, T. Titkova, Modern Probl. of the Earth Rem. Sens. from Space, 11(2), 38-49 (2014) (in Russian)

7. E. Kazakova, M. Chumakov, I. Rozinkina, Russ. Meteorol. Hydrol., 40(5), 296-304 (2015)

8. E. Churiulin, I. Krylenko, N. Frolova, B. Belyaev, IOP Conf.: Earth and Env. Sci., 263 (1) (2019)

9. S. Pyankov, A. Shikhov, N. Kalinin, E. Sviyazov, J. of Geogr. Sci, 28(2), 221-237 (2018)

10. S. Pyankov, A. Shikhov, P. Mikhaylyukova, Ice and Snow. 59(4), 494-508 (2019)

11. G. Rivin, R. Vil'fand, D. Kiktev, I. Rozinkina, K. Tudriy, D. Blinov, M. Varentsov, T. Samsonov, A. Bundel', A. Kirsanov, D. Zakharchenko. Russ. Meteorol. Hydrol, 44(11), 33-45 (2019)

12. S. Pyankov, N. Kalinin, A. Shikhov, R. Abdullin, A. Bykov, IOP Conf.: Earth and Env. Sci, 321, 64-79 (2019) 